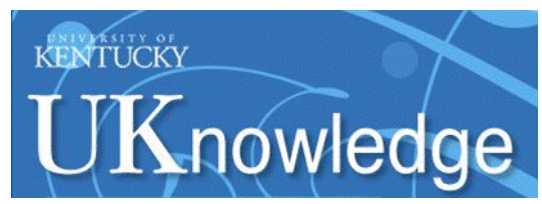

University of Kentucky

UKnowledge

\title{
The Juvenile Justice Behavioral Health Services Cascade: A New Framework for Measuring Unmet Substance Use Treatment Services Needs Among Adolescent Offenders
}

\author{
Steven Belenko \\ Tennessee Temple University \\ Danica Knight \\ Texas Christian University \\ Gail A. Wasserman \\ Columbia University \\ Michael L. Dennis \\ Chestnut Health Systems \\ Tisha Wiley \\ National Institute on Drug Abuse \\ Follow this and additional works at: https://uknowledge.uky.edu/sociology_facpub \\ Part of the Behavior and Behavior Mechanisms Commons, Health Services Research Commons, \\ See next page for additional authors \\ Sociology Commons, and the Substance Abuse and Addiction Commons \\ Right click to open a feedback form in a new tab to let us know how this document benefits you.

\section{Repository Citation} \\ Belenko, Steven; Knight, Danica; Wasserman, Gail A.; Dennis, Michael L.; Wiley, Tisha; Taxman, Faye S.; \\ Oser, Carrie B.; Dembo, Richard; Robertson, Angela A.; and Sales, Jessica, "The Juvenile Justice \\ Behavioral Health Services Cascade: A New Framework for Measuring Unmet Substance Use Treatment \\ Services Needs Among Adolescent Offenders" (2017). Sociology Faculty Publications. 11. \\ https://uknowledge.uky.edu/sociology_facpub/11
}

This Article is brought to you for free and open access by the Sociology at UKnowledge. It has been accepted for inclusion in Sociology Faculty Publications by an authorized administrator of UKnowledge. For more information, please contact UKnowledge@lsv.uky.edu. 


\section{The Juvenile Justice Behavioral Health Services Cascade: A New Framework for Measuring Unmet Substance Use Treatment Services Needs Among Adolescent Offenders}

Digital Object Identifier (DOI)

https://doi.org/10.1016/j.jsat.2016.12.012

Notes/Citation Information

Published in Journal of Substance Abuse Treatment, v. 74, p. 80-91.

(C) 2017 Elsevier Inc. All rights reserved.

This manuscript version is made available under the CC-BY-NC-ND 4.0 license https://creativecommons.org/licenses/by-nc-nd/4.0/.

The document available for download is the author's post-peer-review final draft of the article.

Authors

Steven Belenko, Danica Knight, Gail A. Wasserman, Michael L. Dennis, Tisha Wiley, Faye S. Taxman, Carrie B. Oser, Richard Dembo, Angela A. Robertson, and Jessica Sales 
Published in final edited form as:

J Subst Abuse Treat. 2017 March ; 74: 80-91. doi:10.1016/j.jsat.2016.12.012.

\title{
The Juvenile Justice Behavioral Health Services Cascade: A New Framework for Measuring Unmet Substance Use Treatment Services Needs among Adolescent Offenders
}

\author{
Steven Belenko ${ }^{a}$, Danica Knight ${ }^{b}$, Gail A. Wasserman ${ }^{c}$, Michael L. Dennis $^{d}$, Tisha Wiley ${ }^{\mathrm{e}}$, \\ Faye S. Taxman ${ }^{f}$, Carrie Oserg, Richard Dembo ${ }^{h}$, Angela A. Robertson', and Jessica Sales ${ }^{j}$ \\ aTemple University, 1115 Polett Walk, Philadelphia, PA 19122. \\ bTexas Christian University, 3034 Sandage Avenue, Fort Worth, TX 76129. d.knight@tcu.edu \\ 'Columbia University, 1051 Riverside Drive, Unit 78, NY, NY 10032. \\ wassermg@nyspi.columbia.edu \\ dChestnut Health Systems, 448 Wylie Drive, Normal, IL 61701. mdennis@chestnut.org \\ eNational Institute on Drug Abuse, 6001 Executive Boulevard, Room 5191, Bethesda, MD, 20892. \\ wileytr@nida.nih.gov \\ fGeorge Mason University, 4087 University Drive, 4100, MSN 6D3, Fairfax, VA 22030. \\ ftaxman@gmu.edu \\ gUniversity of Kentucky, 1531 Patterson Office Tower, Lexington, KY 40506. Carrie.oser@uky.edu \\ hUniversity of South Florida, 4202 E. Fowler Avenue, Tampa, FL 33620. rdembo@usf.edu \\ 'Mississippi State University, 1 Research Blvd., Suite 103, Starkville, MS 39759. \\ Angela.robertson@ssrc.msstate.edu \\ jEmory University, Rollins School of Public Health, 1518 Clifton Road, Room 570, Atlanta, GA, \\ 30322. jmcderm@emory.edu
}

\begin{abstract}
Overview-Substance use and substance use disorders are highly prevalent among youth under juvenile justice (JJ) supervision, and related to delinquency, psychopathology, social problems, risky sex and sexually transmitted infections, and health problems. However, numerous gaps exist in the identification of behavioral health $(\mathrm{BH})$ problems and in the subsequent referral, initiation and retention in treatment for youth in community justice settings. This reflects both organizational and systems factors, including coordination between justice and $\mathrm{BH}$ agencies.
\end{abstract}

Correspondence to: Steven Belenko.

Publisher's Disclaimer: This is a PDF file of an unedited manuscript that has been accepted for publication. As a service to our customers we are providing this early version of the manuscript. The manuscript will undergo copyediting, typesetting, and review of the resulting proof before it is published in its final citable form. Please note that during the production process errors may be discovered which could affect the content, and all legal disclaimers that apply to the journal pertain.

Clinical Trials Registration number - NCT02672150 
Methods and Results-This paper presents a new framework, the Juvenile Justice Behavioral Health Services Cascade ("Cascade"), for measuring unmet substance use treatment needs to illustrate how the cascade approach can be useful in understanding service delivery issues and identifying strategies to improve treatment engagement and outcomes for youth under community $\mathrm{JJ}$ supervision. We discuss the organizational and systems barriers for linking delinquent youth to BH services, and explain how the Cascade can help understand and address these barriers. We provide a detailed description of the sequential steps and measures of the Cascade, and then offer an example of its application from the Juvenile Justice - Translational Research on Interventions for Adolescents in the Legal System project (JJ-TRIALS), a multi-site research cooperative funded by the National Institute on Drug Abuse.

Conclusion-As illustrated with substance abuse treatment, the Cascade has potential for informing and guiding efforts to improve behavioral health service linkages for adolescent offenders, developing and testing interventions and policies to improve interagency and crosssystems coordination, and informing the development of measures and interventions for improving the implementation of treatment in complex multisystem service settings.

\section{Keywords}

substance abuse treatment; juvenile justice; delinquent youth; barriers to treatment access; continuum of services; evidence-based practices

\section{Introduction}

The prevalence of substance use and substance use disorders (SUD) among adolescents under juvenile justice (JJ) supervision is much higher than for general community populations, and is related to delinquency, psychopathology, social problems, risky sex and sexually transmitted infections, and other health problems (Clark, 2004; Hicks, Iacono, \& McGue, 2010). An estimated $70 \%$ of arrested juveniles have had prior drug involvement (Belenko \& Logan, 2003), and 78\% have recently used alcohol or drugs (Zhang, 2004).

Adolescent substance use has serious negative consequences for adolescent development, school performance, and increases risk for progression to a SUD in both adolescence (Winters \& Lee, 2008) and adulthood (Englund, Egeland, Oliva, \& Collins, 2008; Stone, Becker, Huber, \& Catalano, 2012; Swift, Coffee, Carlin, Degenhardt, \& Patton, 2008). Arrested youth initiate substance use earlier than other adolescents, leading to more problematic substance use and higher recidivism (Henggeler, Clingempeel, Bronidon, \& Pickrel, 2002; Kandel \& Davies, 1992; Kandel \& Yamaguchi, 2005). Wasserman and colleagues (2010) found that more than a third of a national sample of juvenile delinquents had SUDs, with rates increasing across justice system penetration.

The relationship between substance use and delinquency, however, is not straightforward. Not only do rates differ for specific groups of youth, but recommended treatment approaches also differ depending on their unique needs. For example, the relationship between alcohol use and delinquency is stronger among males and younger youth (Barnes, Welte, \& Hoffman, 2002). Females comprise only $27 \%$ of the national JJ justice population (Scott \& Dennis, 2016), yet have higher rates of anxiety and affective disorders (Wasserman, McReynolds, Ko, Katz, \& Carpenter, 2005). Among adolescents in general, up to $90 \%$ of 
those with a SUD meet criteria for one or more psychiatric disorders (Chan, Dennis, \& Funk, 2008; Kandel et al., 1999). Similar trends are evidenced among JJ-involved youth (Wasserman et al., 2010), which further illustrates the need to provide appropriate treatment to reduce delinquency and increase functionality. Thus, it is critical that the JJ system address the treatment needs of juveniles with SUDs to promote both public safety and improve health outcomes. The capacity of the JJ system to do so remains problematic given the lack of coordination and integration of SUD and mental health services in most communities, a problem that plagues the ability to provide a continuum of care or to provide integrated services. It is well-recognized that adolescent treatment that addresses both substance abuse and mental health needs is more likely to be more effective than treatments that address only one disorder (see Robinson \& Riggs, 2016; NIDA, 2014; Teplin et al., 2005).

Problem identification and triage into appropriate services can be difficult to accomplish, especially in large systems serving diverse groups of youth and where staff must coordinate services across multiple agencies. Improving outcomes for justice-involved youth requires the identification of underlying behavioral health $(\mathrm{BH})$ issues that may be contributing to the youth's delinquency. It is imperative, however, that the system goes beyond simply identifying problems-youth must be referred to appropriate services and agencies from different service systems must collaborate and develop interagency strategies to ensure that youth actually receive these services as intended. Achieving this goal requires effort that crosses organizational boundaries and a systems-level view of how youth are being identified and served. These efforts can be facilitated by reliance on a unifying conceptual framework for illustrating, documenting, and understanding how justice-involved youth move across and between the multiple settings in which they receive services. The Juvenile Justice Behavioral Health Services Cascade framework (hereinafter referred to as the "Cascade") presented in this paper provides an approach, informed by data, to tracking the aggregated movement of youth across these systems and providing a common metric for understanding and comparing diverse systems.

The Cascade framework described herein is not intended to capture all subtleties in the ways in which youth are linked to services, but rather is a first step toward conceptualizing the fundamental elements of a structured service continuum. Our emphasis is on demonstrating how the Cascade model can be used to address unmet substance abuse treatment needs; however, the framework also has broader uses for other BH issues. In its application with SUDs, we argue that all youth who enter the JJ system should be screened for substance use and other BH problems. This screening should be used to determine whether youth are assessed with a more comprehensive and validated assessment protocol and whether they are referred to other services, such as evidence-based prevention or treatment interventions (Models for Change, 2007; NIDA, 2014). The assessment results should then trigger a case plan and specific treatment recommendation (Wasserman, Jensen, Ko, Trupin, \& Cocozza, 2003). Once such a plan is developed, the youth should be referred to an appropriate treatment provider (American Society of Addiction Medicine, 2013), receive a clinical assessment, initiate treatment, and remain engaged in evidence-based treatment for a sufficient length of time to improve outcomes. 
Herein, we describe an optimal continuum of services from screening through treatment engagement, discuss organizational and systems barriers for linking delinquent youth to SUD services, provide a detailed description of the sequential Cascade steps and measures, and offer an example of its application from the Juvenile Justice - Translational Research on Interventions for Adolescents in the Legal System (JJ-TRIALS) multi-site research cooperative, funded by the National Institute on Drug Abuse (NIDA). The Cascade has other potential applications beyond its use in a research environment, such as providing juvenile and treatment agencies with a template for assessing progress in service delivery. This paper focuses on the research application but the discussion also highlights the other potential uses of the Cascade framework.

\subsection{The optimal continuum of services}

The JJ system clearly has responsibility for addressing youth health needs in secure facilities (U.S. Department of Justice, 2016). However, we focus on community supervision because it is the most common JJ supervision type for delinquent youth (Furdella \& Puzzanchera, 2015), and because the challenges of identifying SUD problems and referral/linkage to treatment are much greater than within secure institutional settings (Taxman \& Belenko, 2012, Wasserman et al., 2003). For youth under community supervision there is increasing acceptance that identification of substance use service needs and community services linkage is an effective strategy for reducing recidivism (Evans-Cuellar, Wasserman, McReynolds, Ko, \& Katz, 2006; Hoeve, McReynolds, \& Wasserman, 2013). But much variation exists across jurisdictions in this continuum of substance use services. Some jurisdictions conduct comprehensive assessment and provide treatment services directly, while most rely on community providers. In most JJ systems, youth with SUDs who require treatment will likely be referred to external providers for one or more services (Scott \& Dennis, 2015; Steadman, 1992). A survey of nationally representative sample of counties estimated that of 4,252 primary providers of substance use and mental health services for youth under community justice supervision, 2,823 (66\%) provided both, $778(18 \%)$ provided only mental health treatment services and 651(15\%) provided only substance use treatment services (Scott \& Dennis, 2016). While the growing number of service providers that provide both substance abuse and mental health services is encouraging, the service delivery sequence often breaks down (even at the initial step of screening), and deteriorates further as youth transition from $\mathrm{JJ}$ to community provider agencies for treatment.

Even when cross-system linkages are in place, youth in the $\mathrm{JJ}$ system still are less likely to receive evidence-based practices (EBPs; Belenko \& Dembo, 2003). National data on specialty adolescent SUD treatment programs have shown that the average program had only adopted half of the indicators of high-quality SUD care and EBPs (Knudsen, 2009). Even for youth treated in secure facilities (where service provision is presumably achieved more smoothly), access to EBPs is limited (Burney-Nissen, Butts, Merrigan, \& Kraft, 2006; Office of Applied Studies, 2000). Ultimately, the effectiveness of the Cascade depends on agencies' ability to provide evidence-based services, and to keep young persons engaged in services long enough to benefit from them. 


\subsection{Challenges in addressing behavioral health needs}

Organizational and systems factors affect the ability of agencies to address BH needs. First, the different missions of the $\mathrm{JJ}$ and $\mathrm{BH}$ treatment systems lead to different priorities and goals. The primary focus of community JJ system agencies is on public safety, social control, and efficient case processing, with identifying or addressing $\mathrm{BH}$ service needs a secondary goal (Belenko \& Dembo, 2003; Taxman, Henderson, Young, \& Farrell, 2014; Wasserman et al., 2009). By contrast, BH systems are interested in identifying and treating SUD and/or mental health issues, regardless of a youth's delinquent behavior.

Second, as with other complex service systems, there is often problematic or inconsistent collaboration and information exchange across JJ and BH service sectors (Aarons, Hurlburt, \& Horwitz, 2011; McGovern, Lambert-Harris, Gotham, Claus, \& Xie, 2014; Proctor et al., 2009). Interorganizational linkages between community JJ agencies and community-based assessment and treatment providers are rarely smooth (Belenko, Sprott, \& Petersen, 2004; De Leon \& Jainchill, 2012; Young, Dembo, \& Henderson, 2007). Reasons include lack of shared mission across systems, competing priorities for JJ staff, lack of an incentive structure to promote JJ staff interest in identifying service needs and making referrals, and lack of information exchange across systems (Snyder \& Sickmund, 2006; Taxman \& Belenko, 2012).

Given varying goals, missions, and operations, $\mathrm{JJ}$ and $\mathrm{BH}$ organizations must collaborate to ensure that youth's needs are being met (Henderson \& Taxman, 2009; Roman, Butts, \& Roman, 2011). Examples range from sharing physical space, manuals, forms, or staff, to joint training and operational procedures, to co-location of services. Effective collaboration can facilitate and help monitor transitions from one system to another, facilitate use of assessment information to match youth to appropriate programs, and promote active case management (e.g., making or managing appointments, providing transportation) to improve treatment engagement and retention. In systems of care where services are more likely to be coordinated, EBPs are also more likely to be adopted (Lehman, Fletcher, Wexler, \& Melnick, 2009; Taxman \& Bouffard, 2000), a broader range of programs and services are offered (Taxman, 1998), and the operational practice tends to mimic integrated care (Drake, 2011).

Third, JJ staff members are seldom well-trained on SUD and other BH issues (Boesky, 2001; Grisso, Barnum, Fletcher, Cauffman, \& Peuschold, 2001; McLellan \& Meyers, 2004), and may not recognize the importance of good assessment, case planning, and referral to adequate services that address a youth's specific needs. They are also not sufficiently familiar with programming to know when youth are receiving integrated care for SUD and mental health or treatment for merely one disorder. Legal and procedural protections can also present a barrier to sharing information where providers face health care system restrictions (e.g., HIPAA restrictions on information exchange).

The complexity of the process means that it is difficult for service providers and researchers alike to organize, collect, and analyze data across the Cascade stages, limiting the ability to identify system gaps and problems at various key points. An organizing framework and associated tools can help clarify the process, detect data and service needs, and identify 
cross-systems linkage points (including potential opportunities for making cross-systems referrals and sharing information). Such a framework can help agencies and policy makers understand how the process is working, determine where improvements are needed, and inform development and testing of interventions to improve linked service delivery at each phase.

\section{The Juvenile Justice Behavioral Health Services Cascade}

The Juvenile Justice Behavioral Health Services Cascade was developed by NIDA's JJTRIALS team. JJ-TRIALS is a research cooperative (including six research centers, a coordinating center, and NIDA) that is experimentally testing a multi-site implementation intervention protocol to (1) reduce unmet substance use treatment needs among delinquent youth under community supervision, and (2) increase use of EBPs. The overall study design is described in detail elsewhere (Knight et al., 2016). In brief, the study involves delivering a multi-component training, and technical assistance intervention to $35 \mathrm{JJ}$ agencies (primarily probation departments) and their $\mathrm{BH}$ partners that provide substance use treatment services. Training and technical assistance focuses primarily on helping agencies identify and select goals to reduce unmet substance use services needs among the youth they serve. Half of the sites are randomly selected to receive additional support through external facilitation of a local change team tasked with pursuing the selected goals.

The Cascade is a unifying conceptual framework designed to help identify research questions, hypotheses, potential interventions, and data collection needs, and to serve as a platform for guiding study sites to the selection of goals to reduce unmet service needs. As youth with substance use service needs move through the JJ system, there are multiple opportunities to engage youth in treatment services. For youth under community JJ supervision, the process is complicated by the fact that they are commonly screened in a community JJ setting, but typically receive treatment services in community specialty care sectors, requiring them to navigate multiple systems, and making a focus on cross-system linkage and information sharing essential for effective care. It is a complex, multi-stage and multi-system process. The Cascade was designed to help JJ and BH staff understand this process and track changes in youth services over time.

\subsection{The HIV Care Cascade}

The concept of sequential stages of SU treatment services from problem identification through treatment engagement has existed for many years (Scott \& Dennis, 2009, 2011), but the structure and visual representation of the Cascade was particularly informed by the HIV care cascade, which has emerged in recent years as a widely used framework for both depicting gaps in HIV surveillance and treatment, and for estimating the impact of interventions to increase engagement in treatment and viral suppression to undetectable levels. The HIV cascade has been used to describe the HIV epidemic at local, national, and international levels, with successive bars illustrating the numbers of individuals subsequently diagnosed, linked to care, retained in care, receiving antiretroviral therapy, and achieving viral suppression (Gardner, McLees, Steiner, Del Rio, \& Burman, 2011; Greenberg et al., 2009; MacCarthy et al., 2015). It provides a quantitative visual depiction of the various 
service and medical stages needed to maximize HIV medical care from initial diagnosis through viral suppression (the ultimate public health goal).

The HIV care cascade has predominantly used outcome-focused population-level estimates to illustrate and isolate where individuals are "lost" in the care continuum (Mugavero, Amico, Horn, \& Thompson, 2013). The HIV cascade has been embraced by the United States HIV/AIDS Strategy and the World Health Organization (White House Office of National AIDS Policy, 2010). The rapidity with which the HIV cascade has been adopted by HIV providers, researchers, and policy-makers speaks to its relative simplicity, visual power, and applicability to examining a number of aspects of HIV care. We recognize that significant differences exist between HIV and BH care systems, such as (1) differences in professional training and salaries; (2) more streamlined referrals within the medical system for HIV care, between providers with similar goals, and (3) clearer and more standardized treatment protocols in the HIV care system. However, the cascade concept and its visual depiction of data provide a common vocabulary that can facilitate efforts to achieve public health goals in different populations and settings.

\subsection{Components of the Juvenile Justice BH Services Cascade}

The Cascade (Figure 1) comprises six distinct interrelated activities that are essential for identifying substance use problems and triaging youth into appropriate clinical services. These include screening, assessment, identification of need (a discrete activity because screening and assessment results must be reviewed before a determination of need is made), referral to treatment, initiation, engagement, and continuing care. Implicit in the design of the Cascade is the idea that as youth transition across these service systems, communication and coordination is required between the justice system and the treatment providers. The Cascade focuses on SUD-related services. While it is recognized that a focus on integrated BH services (substance abuse and mental health) is desirable, the Cascade was initially created as a tool to identify utilization of various services which did not differentiate whether the treatment involved integrated care.

As indicated previously, many $\mathrm{JJ}$ agencies rely on independent community agencies to provide services along the Cascade. However, transition points, as well as location and purveyor, vary by jurisdiction. Bars on the left in Figure 1 (depicted in red) indicate services that would ideally occur within JJ settings (i.e., screening), in order to reach as many youth as possible. Indeed, screening is administered by JJ agencies in most JJ-TRIALS sites. Bars in the middle (depicted in purple) indicate a transition or "hand-off" from one agency to another (i.e., JJ referral to a provider for treatment), presumably after decisions have been made with regard to needed services. Bars on the right (depicted in blue) indicate engagement in treatment services. While some JJ agencies do provide services directly, the majority do not (Scott \& Dennis, 2016). It is important to note that transitions can occur at nearly every point in the Cascade. JJ referral to treatment providers for assessment and identification of need is indicated by striped purple bars. Although not depicted, transitions can also occur between providers as youth engage in a continuum of care (transitioning to higher or lower levels of care; ASAM, 2013). 
2.2.1. Screening and assessment-Over the past two decades, greater focus has been placed on promoting $\mathrm{BH}$ screening in the JJ system, with recommendations for specific instruments. However, little attention has been paid to the entire process that should occur within a screening protocol and the sequence of linked events that should follow. As outlined by the World Health Organization (Wilson \& Jungner, 1968), and more recently applied to the JJ system (Models for Change, 2007), screening is intended to be universal and aimed at identifying conditions not already known. Screening should also include procedures to ensure that youth who screen positive are systematically assessed further, and ultimately linked to care. Recent efforts to screen adolescents for substance use, depression, and anxiety during regular pediatrician visits provide a model for how universal screening might be accomplished in other settings (Sterling, Kline-Simon, Wibbelsman, Wong, \& Weisner, 2012; Wissow et al., 2013).

Effective screening should help efficiently and reliably identify potential BH problems in otherwise unidentified individuals (Lessler, 1972; New York State Department of Health, 2015; Wilson \& Jungner, 1968). Ideally, screening should (a) rely on a standardized validated instrument that is evidence-based, (b) be administered to all youth being processed, (c) rely on a relatively brief set of questions, (d) be suitable for administration by either clinical or non-clinical staff (although clinician review may be sometimes needed to resolve questions), and (e) generate clear decision rules regarding where and for what purpose a youth is referred on for additional clinical assessment. Universal screening is costefficient because it allows more time consuming and costly assessment to be reserved for those youth more likely to have a SUD. This is important, as recent national survey data indicates that screening in community justice settings is not universal, and often contracted out to other agencies (Scott \& Dennis, 2015; 2016).

Although recent efforts have prompted improvements in identification of $\mathrm{BH}$ concerns (Wachter, 2015), use of validated instruments remains low, with fewer than half of juvenile probation agencies in an earlier national survey using a standardized tool to screen or assess for SUDs (Young et al., 2007). In a recent nationally representative survey of juvenile probation agencies, only 53\% reported conducting any screening for substance use or BH problems, $42 \%$ used standardized tools, and $38 \%$ used standardized tools on over half their youth. Only $11 \%$ conducted a more detailed clinical assessment $(10.6 \%$ with standardized tools), and $6 \%$ used standardized assessment tools on $50 \%$ or more of youth (Scott \& Dennis, 2015).

Assessment for $\mathrm{BH}$ problems is more comprehensive and multidimensional than screening and is designed to support diagnosis, placement, and treatment planning related to substance use and related problems (e.g., HIV risk, mental health disorders; Wasserman et al., 2003). A formal clinical assessment should (a) be conducted by trained clinical professionals, (b) rely on instruments or components that are evidence-based, and (c) address BH problem symptoms and diagnoses and related topics (e.g., treatment history, family history of $\mathrm{BH}$ problem, psychosocial history, barriers to care, amenability to treatment, functional impairment; ASAM, 2013; SAMHSA, 2015). 
In a large national survey of juvenile probation agencies (Scott \& Dennis, 2015), approximately three-fourths reported referring youth on to BH agencies for assessment, rather than conducting the assessments themselves. This has implications for the placement of the "Referral" bar of the Cascade: depending on jurisdiction, it may reflect Screen/ Assess/Refer or Screen/Refer/Assess. Importantly, the same survey documented that BH assessments were more likely to rely on EB components when they were conducted in the $\mathrm{BH}$ agency itself than when they were conducted in the JJ setting. Keeping in mind the far greater cost of assessment activities, relative to screening activities, a public health approach to structuring relationships between screening and assessment activities allows for agency resources (budgetary, staffing) to be most clearly directed to clients with greatest need.

Our experience to date in JJ-TRIALS reveals that the timing and placement of assessment in the Cascade may vary across jurisdictions. In some systems, assessment is completed prior to treatment referral (e.g., court officers collect all relevant information prior to disposition hearing and referral may be made as part of a court order), while in other systems assessment is completed as part of a treatment referral (e.g., the BH provider does the assessment to determine appropriateness for treatment).

2.2.2. Identification of need-Identification of need is conceptualized as a discrete activity in the Cascade because screening and assessment results, as well as other information (e.g., current or past history of treatment, prior assessments), must be reviewed in order to inform case planning and subsequent referral (ASAM, 2013). Level of need can be conceptualized as a continuum, ranging from no use/no need to drug dependence, with classifications based on recommendation from assessment or screening results corroborated by another source (e.g., urinalysis results, parental report, treatment records). Level of need should then inform treatment referral—whether a referral should occur (i.e., substance use is above a designated threshold) and what level of care the youth should receive (e.g., outpatient versus residential level of care, recommended duration).

Traditional patient placement principles and criteria suggest that matching youth to services based on the specific needs of the youth will yield better clinical outcomes than providing generic programming (Childs \& Sullivan, 2013; Taxman and Caudy, 2015). But when youth are placed in the wrong programming or not given sufficient treatment exposure, clinical outcomes are suboptimal. Treatment matching can help maximize the likelihood that youth receive treatment that addresses their specific needs, and reduces the complexity of service delivery by allowing the program to focus on clients with similar needs. Ideally, evidencebased prevention or early intervention programs should be available for addressing the needs of youth who may not have problems of sufficient severity to warrant more intensive or formal treatment.

2.2.3. Referral-To be most effective, referral to substance use treatment should entail an active approach, whereby JJ staff work to link the family to services (Wasserman et al., 2009). This active approach could include making a phone call to a specific agency with parents present, rather than providing families a list of possible providers and encouraging them to call. It could also involve help with scheduling appointments, providing reminders, assisting with transportation, and following up to confirm that the family showed up. More 
generally, effective referral strategies may also include agreements with providers that specify the target population, the type and intensity of services offered, and the nature of pre-referral contact between juvenile probation staff and BH intake staff (for confirming eligibility, insurance coverage, hours of operation, and availability of a treatment slot). These strategies are especially important if the family is not supportive of treatment, which is often encountered in JJ settings.

2.2.4. Treatment initiation, engagement, and continuing care-We note that efforts to actively refer youth to appropriate services do not ensure that youth will receive those services. Consequently, it is critical to include in the Cascade the core stages of treatment process such as initiation, engagement, and continuing care. These measures were selected because they are recommended as policy indicators of service providers bolstered by empirical evidence that they are meaningful predictors of improved client level outcomes (Garnick et al., 2012; Hser et al., 2001; National Institute on Drug Abuse, 2014).

Treatment initiation refers to attending the first appointment with the provider. The "handoff" between JJ and treatment represents one of the most likely places for youth to "fall through the cracks," even if services are provided internally by the JJ agency. The last two activities, engagement and continuing care, are contingent on initiation-one cannot engage or continue in services if the initial appointment has not occurred. Treatment engagement refers to the initial treatment contacts. The Office of National Coordinator performance criteria for health care reform suggests 2 or more sessions within 6 weeks (Office of National Coordinator, 2015). This is similar to the Washington Circle definition of treatment engagement (at least 2 treatment visits in the 30 days following treatment initiation), which has been found to predict reduced substance use for adolescents at sixmonth follow-up (Garnick et al., 2012). Continuing care refers to a longer-term approach to rehabilitation that might include multiple treatment episodes or aftercare. We defined this as a minimum of 3 months in treatment, based on NIDA's principles of adolescent SUD treatment (NIDA, 2014; see also Hser et al., 2001) which indicates improved outcomes for youth who engaged in treatment for at least three months and who participate in posttreatment continuing care (e.g., drug use monitoring, follow-up visits, and support groups such as 12-step programs).

At each stage of the Cascade, timing, quantity, and quality of services are also important. The National Commission on Quality Assurance (NCQA; National Commission on Quality Assurance, 2013), National Quality Forum (NQF, 2012), and Office of National Coordinator (ONC) of Healthcare Reform (ONC, 2015), have all adopted standards that operationally define the initiation of and engagement in alcohol and other drug treatment. Unfortunately, only about one-third of providers met standards for timely initiation and fewer than $20 \%$ met engagement standards (NCQA, 2013). When compared against standards for screening and assessment, use of EBPs, availability of continuing care, and staff qualifications (e.g., American Society of Addiction Medicine, Commission on the Accreditation of Rehabilitation Facilities, Council on Accreditation, Joint Commission), publicly funded substance abuse treatment programs were recently found to meet only 6 of 14 indicators of quality treatment at least $80 \%$ of the time (Hunter, Griffin, Booth, Ramchand, \& McCaffrey, 2013). While application of the Cascade will not in itself improve use of EBPs, it serves to 
highlight the importance of employing quality practices and measures across the Cascade if youth needs are to be fully met. Thus, a key element of the JJ-TRIALS staff training focuses on identifying and selecting appropriate EBPs for each stage of the Cascade. A full discussion of ways to increase EBP use is beyond the scope of the paper; however, several resources for identifying, selecting, and implementing EBPs exist (Manuel, Hagedorn, \& Finney, 2011; OJJDP, 2016; SAMHSA, 2016).

\subsection{Measuring steps within the Cascade}

EBPs can be mapped onto each of the steps along the Cascade. The availability and use of these practices, as well as the successful handoffs or transitions between steps can be systematically measured, providing useful insight into how youth move through the Cascade, the quality of services available, and the degree to which services are utilized. Table 1 shows the definitions and formulas for measures at each step of the Cascade (developed according to standards set by organizations listed above). Determining the definition of the "denominator" is important for calculating performance rates at each stage. Using the lettered steps on the left, the performance rate for each step is shown as a formula on the right. The number of clinical assessments and the number in need would typically be a subset of those screened, because there may be structural reasons why a youth screened for substance use does not receive an assessment (e.g., the delinquency case is dismissed or otherwise closed, or the youth is already in treatment). Similarly, there may be valid reasons why a youth may not receive the appropriate next step in the Cascade; systems are not likely to ever serve $100 \%$ of those in need. Those unserved in a later Cascade steps (e.g., those referred but who do not enter treatment) represent "unmet needs" and are potential targets for further interventions or policy improvements.

In addition to the rate of retaining youth at each Cascade step, there is also value in characterizing "quality" dimensions. To focus only on the percentage of eligible youth receiving services at each step would not be meaningful if lower quality or poorly matched services are delivered or if there is a long delay in providing the needed service. Table 2 summarizes suggested targets for the timing between each step and other quality indicators related to content or procedures. These are the benchmarks being applied in the JJ-TRIALS project, which were informed by those promulgated by NCQA, NQF, and other entities (see above).

\section{Application of the Cascade in JJ-TRIALS}

The primary JJ-TRIALS study uses a cluster randomized design to test the effectiveness of two implementation interventions (Core and Enhanced) for promoting improvements in substance use service delivery (Knight et al., 2016). The Cascade serves as a framework on which research questions, intervention protocols, and measurement strategies are based. First, a primary hypothesis states that the intervention will increase the percentage of youth "retained" at each stage of the Cascade. The Cascade framework specifies that (1) substance use services involve six distinct, yet interrelated activities; (2) gaps in receipt of these services can be conceptualized as "unmet need;" (3) because service areas are conceptualized as interconnected, improvement efforts should address outcomes (reducing 
gaps) across all services in the continuum; and (4) change in an earlier Cascade bar will likely affect later Cascade bars (e.g., changes to screening will affect who is assessed; changes to referral will affect who initiates).

Second, the Cascade informs key elements of the JJ-TRIALS study's intervention components. The Cascade provides a framework for developing content for staff training, reinforcing JJ staffs' understanding of the importance of screening, assessment, appropriate referral, and treatment engagement. There are four key intervention components (for more detailed descriptions of these components, see Knight et al., 2016):

1. The JJ-TRIALS Behavioral Health Training materials focus on specific best practices associated with each Cascade step and on strategies for ensuring appropriate and efficient movement from one step to the next. The $\mathrm{BH}$ training focuses on substance abuse but also addresses mental health issues.

2. The agency-level Needs Assessment includes exploration (and detailed mapping) of the local JJ system showing the key points at which the various stages of the Cascade occur, as well as which agency and staff are responsible. The Needs Assessment activities solicit detail (from the perspectives of both $\mathrm{JJ}$ and $\mathrm{BH}$ staff) on linkage and service delivery points, quality indicators of the Cascade components (e.g., what screening and assessment practices are used, how are staff trained on those procedures), and how information is shared across agencies.

3. The Site Feedback Report (SFR) uses the Cascade graphic to organize and depict local results from three data sources: Needs Assessment, de-identified youth records, and JJ/BH agency survey responses. The SFR presents staff with the site's youth service data, in terms of (a) retention (percentages of youth receiving a service or being "retained" in the Cascade across bars), (b) timing (number of days between various points in the Cascade), and (c) details regarding service delivery pertaining to each bar in the Cascade (including the specific tools used, strengths and challenges in the local site). The SFR concludes with a menu of possible goals that map onto the different steps of the Cascade. Data from the site are reported next to each potential goal, and this information is used by the local team to help select one goal to work toward over the course of the 12month experiment period. Ideally, the chosen goal corresponds to a step in the Cascade and requires some level of inter-agency collaboration.

4. Informed by the SFR, the first part of the Goal Achievement Training (GAT) establishes and trains local teams (including JJ and BH staff) to (a) identify gaps and build consensus across all agencies regarding what areas within the Cascade need attention, (b) narrow down potential goal options, (c) determine which goals are measurable, and (d) select a Cascade-related goal. The second GAT session emphasizes the importance and utility of Data Driven Decision Making (DDDM; Marsh, Pane, \& Hamilton, 2006) and instructs teams on use of PlanDo-Study Act rapid cycle testing procedures (McCarty et al., 2007; Moule, Evans, \& Pollard, 2013; Taylor et al., 2014) for implementing and testing the selected goal. 
Third, the Cascade informs measurement procedures and instrument development. Data related to the various bars in the Cascade are used to measure and observe progress toward the selected goal. Cascade data are generated from a combination of electronic and paper case records. In addition to providing Cascade data in the initial SFR, JJ-TRIALS Research Centers also generate quarterly reports on retention within the cascade (based on cohorts of youth entering the JJ system), and a final SFR summarizing changes since the baseline (including retention, timing, and detail within the Cascade).

In each of the intervention components described above, the Cascade is used as a framework for collecting, synthesizing, and/or interpreting information as it relates to youths' receipt of SU services. The critical elements of the Cascade are defined and described in training. The degree to which Cascade elements are being implemented within the JJ system is assessed through the Needs Assessment and depicted visually (and presented to leadership) in the SFR. Strategies for how to continue to assess movement through the Cascade and address deficiencies in services is the subject of GAT training. In addition to these components and quarterly Cascade data reports, the Needs Assessment and SFR are repeated at the end of the project experiment to provide site leadership with feedback on change over time. Interagency workgroups are encouraged to examine their own data to monitor changes in their Cascade-related goal, and consider (a) how their efforts might be impacting other bars in the Cascade and (b) whether they should turn attention to a new goal (perhaps in another stage of the Cascade).

\subsection{Challenges encountered}

Over the approximately 18 months that the Cascade has been used in JJ-TRIALS, the primary challenge to its utilization has been related to data collection, especially for later Cascade steps (past screening and assessment). In general, JJ management information systems focus on case processing data (to ensure appropriate legal proceedings). JJ agencies and their probation officers are not routinely asked to report on BH services, and generally do not have incentives to capture service delivery information in JJ databases. The JJ database systems in the 35 study sites (and generally across the U.S.) typically capture the "front end" stages (i.e., intake into JJ and screening), but rarely capture (in electronic form) complete information from the BH services provider on treatment referral, initiation, or engagement in treatment. ${ }^{1}$ This information is often recorded in the provider's electronic records or in paper/electronic case notes, but both cannot readily be linked to JJ data systems. Information may be recorded in JJ paper case files or electronic case notes, but data extraction of text files is difficult, time consuming, and costly. Further, case files may be difficult to find or located in multiple offices. Staff turnover may result in loss of information, especially if documentation has been inconsistent. It can be difficult to determine if a lack of recorded treatment information means that the service did not occur, or did occur but was not recorded in a retrievable form. The adoption of newer electronic record systems in some JJ-TRIALS sites aimed at capturing assessment results, treatment

\footnotetext{
${ }^{1}$ Data from the JJ-TRIALS national survey of juvenile justice agencies indicate that $68 \%$ have an electronic records system that can track substance abuse or mental health screening or clinical assessment data (Scott \& Dennis, 2015).
} 
referrals, and treatment service dates has helped address many of these data collection challenges.

Another challenge is that definitions of what constitute "screening," "assessment," "substance use problem," "treatment need," and "appropriate treatment," vary across JJ jurisdictions. When a state mandates the use of a particular screening instrument, the ways in which the instrument is employed (when administered, to whom, how results are used, whether results are used) also may differ across jurisdictions. Many juvenile courts and probation agencies use drug testing to screen incoming youth and to determine treatment need; such information may be useful for determining recent drug use, but is insufficient as an indicator of treatment need. If a screening instrument is used, it may not be evidencebased, or universally administered. Juvenile court intake and probation staff conduct assessments of criminogenic needs and recidivism risk in order to make case disposition and services recommendations. They typically do not conduct clinical assessments for diagnostic purposes and determination of appropriate level of care, but rely on treatment providers for this function. If $\mathrm{JJ}$ staff members are conducting clinical assessments, they often are not using an evidence-based or standardized tool (Young et al., 2007). The Cascade framework does not depict whether the youth are placed in evidence-based treatments, integrated SUD and mental health care, or other key features of treatment. However, the Cascade is readily adaptable to add or modify bars that include delivery of evidence-based or integrated services.

Finally, there are limitations that could complicate dissemination and scaling up of the Cascade framework beyond JJ-TRIALS. First, the Cascade is an ideal representation of the sequence of events that should occur in the process of linking young offenders with appropriate services. While our conceptualization focuses on a single primary path, the reality can be more complex. Youth who enter treatment may drop out and need to be referred again. Youth who are not assessed or referred may choose to go to treatment on their own (or based on referral from a parent or lawyer), or they may already be in treatment at the time of their offense and referral to JJ. Court proceedings and legal counsel can also impact the timing and receipt of services, further complicating the process. For example, attorneys might advise against clinical assessment (especially during the early stages of case processing) or judges can order treatment independent of screening or assessment results. Although we have collected data on these other paths for future investigation, exploring all possible paths is beyond the scope of this paper. Second, it is likely that agencies and systems wishing to use the Cascade outside of a research setting would need to receive some training and technical assistance in order to maximize its utility.

\subsection{Positive initial outcomes resulting from Cascade use}

During initial interactions with JJ-TRIALS study sites and discussions of data issues related to the Cascade, several potential solutions to the challenges of populating the Cascade charts have emerged. First, using the Cascade as a conceptual foundation for the Needs Assessments and SFRs has helped JJ and BH leadership grasp the utility of collecting, analyzing, and using this information, as well as the importance of accurate recordkeeping. We are working with site leadership and data systems managers to develop processes and 
procedures for capturing the data more efficiently and accurately. For example, in several jurisdictions we are collaborating with Information Technology staff to add data fields related to the Cascade to the electronic data system. Another clear benefit is that in several sites, agency leadership is increasing efforts to train line staff on documenting treatment service-related activities accurately and in a timely manner. Finally, it will become important to set up systems for regularly monitoring Cascade data and providing feedback to site staff. Quarterly Cascade reports will fulfill this function, while also providing feedback to the sites on how well they are meeting the goals that they have selected for improving selected aspects of the Cascade process.

\section{Implications for Substance Use Treatment System}

\subsection{Benefits from an organizational perspective}

A visual representation that captures and summarizes key elements needed to identify SUDs and link individuals to appropriate services has several potential benefits for $\mathrm{JJ}$ and $\mathrm{BH}$ organizations: facilitating increased awareness of best practices for substance use services, improving interagency collaboration and communication, and providing a platform for monitoring, evaluating, and improving performance. Further the Cascade can focus attention on the nature of the services available given the screening and assessment information.

\subsubsection{Facilitating increased awareness of best practices for substance use-}

The Cascade can be used as a training tool for both JJ and SUD or BH treatment staff. It operationalizes the steps, sequences, and quality indicators needed to respond effectively to youth substance use problems, as well as how and what interagency collaborations are needed to achieve significant treatment gains. Training administrative staff on the Cascade may help to facilitate JJ and treatment systems' commitment to providing EB treatment services to delinquent youth in the community by increasing willingness to focus resources and staff time on improving performance along the Cascade. Training line staff (e.g., probation officers, case managers) on Cascade steps may also benefit youth by encouraging staff to (1) embrace the use of EBPs in core areas of screening, assessment, (active) referral, and treatment programming, (2) monitor and where feasible reduce the time between Cascade events, (3) support interagency collaboration and communication (especially when sharing information regarding assessment or treatment attendance); and (4) support improvements in information systems infrastructure to facilitate collection and accuracy of Cascade data.

\subsubsection{Improving interagency collaboration and communication-The Cascade} can also be used to facilitate coordination, collaboration, and information sharing between JJ agencies and providers. Using a graphic tool such as the Cascade can provide a common taxonomy, help to articulate shared goals, identify key cross-systems transition points and stages at which coordination and data sharing are needed, and illustrate areas in need of improvement (Dansereau \& Simpson, 2009). It may also be helpful in facilitating conversations and ultimately foster the development of a common mission across the JJ and BH systems. 
Challenges encountered in interagency collaboration and information sharing should result in modifications/improvements in procedures, practices and data collection. One expected result is improved understanding between $\mathrm{JJ}$ and treatment agencies of one another's roles and responsibilities in substance use service delivery. Another is potentially better integration of services provided by multiple agencies, as leadership and policymakers work together to apply the Cascade to their specific populations and service networks. Together, they can explore problem sources, brainstorm potential solutions, and identify where additional training and interagency collaboration are needed to more effectively respond to youth treatment needs.

\subsubsection{Platform for monitoring, evaluating, and improving performance-Using} the Cascade as a framework for monitoring system performance has the potential to benefit the local JJ and $\mathrm{BH}$ systems because performance-oriented organizations tend to adopt more EBPs (Friedmann, Taxman, \& Henderson, 2007; Taxman \& Belenko, 2012). Here, performance refers to the establishment of set goals, the ability to assess how well the system is doing in obtaining these set goals, and the ability to coordinate data across systems. The focus on performance at each stage of the Cascade, then, can identify gaps in services and procedures as well as the ability to assess how individual agencies are facilitating youth access to care. It removes the potential discomfort of focusing on only one agency when gaps in services are observed, rather than acknowledging systems and interagency issues that are common in multisystem settings (Taxman \& Belenko, 2012).

The Cascade framework is not meant to depict a static process, but one that is adaptable and can evolve over time. Accordingly, Cascade data could be used to understand how the substance use service delivery system needs to be calibrated, and modified to accommodate changes in the funding and regulatory environment, emergence of new drugs (e.g., synthetic or designer drugs) and new patterns of use, and development of new assessment, treatment, and data monitoring technologies. Service delivery systems need to be able to respond effectively to the changing adolescent substance use and treatment landscape. At the same time, the Cascade provides a sequential, patterned service delivery model which has the potential to inform effective responses to these issues.

Consequently, the Cascade can be used as a mechanism for data-driven decision making. Key stakeholders representing various agencies can collect data and depict findings using the Cascade graphic. The information can then be used to inform decisions that will help improve, refine, or reform a range of outcomes and practices (Marsh et al., 2006).

Populating the graphic with actual data makes the Cascade relevant to all stakeholders and enables individuals from multiple agencies opportunities to interpret data according to their own agency's perspective, further facilitating the exchange of information and ideas. Strengths in the way youth are served can be acknowledged, and gaps can be identified and addressed. Reviewing the data at regular intervals provides accountability and can be used to document improvement and/or identify additional areas in need of attention. For example, monitoring performance along the Cascade can inform areas where receipt of services is less than ideal (e.g., $40 \%$ of youth are "in need" of treatment, but only half of those in need are referred for services; lengthy delays in getting screened or assessed). The Cascade framework can also be used by agencies to determine whether subgroups of youth (e.g., 
females, youth with comorbid mental health disorders) are progressing through the steps at different rates than other youths (and whether targeted interventions are needed), or whether sizeable numbers exhibit lower levels of substance use and might benefit from prevention or early intervention. Programming and placement adaptations such as these can potentially impact successful movement through the Cascade. As agencies use the Cascade to study their own systems, they ideally would not only modify service provision but would also adapt the visual Cascade to reflect those modifications (e.g., depicting decision points or thresholds for early-intervention versus outpatient treatment referral decisions).

\subsection{Benefits to youth and their families}

The Cascade provides a comprehensive picture of the substance use services continuum-from identification, to intervention, to follow-up care. Seen in this way, it is more likely that informed, integrated service delivery systems can be developed to better serve justice involved youth with substance use issues, and their families. The fuller depiction of the steps in the Cascade can be used to educate youth and their families regarding what they should expect in this process. JJ clients and their parents/families are often ill-informed about the substance use service continuum (Burney-Nissen et al., 2006; Wasserman et al., 2009). Knowledge about this process can help them more clearly understand important points of contact and transition, and empower them in the key role they play as a catalyst and supporter of their child's recovery.

\subsection{Implications for organizational change and implementation science}

The Cascade provides a visual tool that can be useful for JJ and treatment stakeholders, administrators, and staffs seeking to increase access to services for SUD-involved youth. Visualizing and understanding how the system operates can be useful to begin to build processes that allow for more collaborative or integrated services. Lehman et al. (2009) found that systems that were collaborative and integrative were more likely to implement EBPs. The Cascade can also be a useful training tool, for both JJ and BH staff, on the need for a common mission and goals that emphasize the importance of SU and related treatment services for delinquent youth. The visualization of the Cascade provides the opportunity to view the outcomes of their intake and referral processes in such a manner that it can be used to develop refinements and measure outcomes. This helps move away from the perception that it is the "unmotivated" youth that does not engage in services to a perspective that the system also has barriers to services access. Also, it allows for more attention to helping staff understand concepts underscoring EBPs which should increase their willingness to engage in implementing them (Taxman et al., 2014). Recent studies have found that in addition to training, staff need coaching that reinforces the use of EBPs but also provides guidance on how to apply the EBPs in actual situations to improve youth outcomes (Taxman et al., 2014; Young, Farrell, \& Taxman, 2013).

Finally, existing implementation science models, such as the EPIS model (Aarons et al., 2011) or Consolidated Framework for Implementation Research (CFIR; Damschroder et al., 2009) could be used to inform research on various aspects of the Cascade. These models emphasize the importance of key domains that can influence program implementation, such as (1) intervention characteristics; (2) outer setting or the stakeholders affecting the 
environment or social context; the (3) inner setting including structural factors, culture, climate and readiness for change; (4) individuals involved and their knowledge, organizational commitment and motivation; and (5) the implementation process or change strategy. It would be useful to analyze the Cascade model by these domains to get a more refined sense of the implementation issues at each phase. This could help build a knowledge base about the factors that affect cross-system efforts related to adoption and implementation of improved treatment services for youth.

\section{Discussion}

Recent decades have seen an increased use of screening and assessment procedures in community JJ settings, including the use of evidence-based instruments in many jurisdictions, in making treatment recommendations (Models for Change, 2007). At the same time, although ongoing referrals to treatment service providers are common in the JJ system, treatment program linkage, engagement and follow-up care, all critical elements in reducing involvement in substance use, remain underdeveloped activities in many jurisdictions. Although a somewhat simplistic representation of what can be a complex process, the Cascade highlights critical points of contact and transition in the treatment continuum to inform the identification of unmet needs by $\mathrm{JJ}$ agencies and treatment providers. The Cascade framework seeks to guide systems to use EBPs, data-driven decision making, and audit and feedback. But the ultimate impact on youth outcomes also depends on the implementation or expansion of EBPs, and JJ and BH staff training in the use of the Cascade needs to emphasize the importance of service quality and use of best practices, guided by existing EBP guidelines and repositories (NIDA, 2014; OJJDP, 2016; SAMHSA, 2016).

The various steps in the Cascade correspond to measurable activities that should occur in a logical sequence, and that may involve multiple agencies and "handoffs" across service systems. A number of key policy and service delivery questions arise from the Cascade: What proportion of those at JJ system intake is screened for SU and related service needs? What proportion of those with identified need is referred on to treatment services? What proportion of those who initiate treatment is retained long enough to benefit? Are shorter periods between steps associated with higher retention at the next step? As such, this model and the quantitative tracking that follows from it are broadly applicable for use in any healthcare or social services delivery system, where there is a defined sequence of measurable events that need to occur across systems for optimal delivery of services appropriate to the needs of the clients. Although we developed the Cascade as a framework for studying and improving substance use treatment services for youth under community JJ supervision, the model is readily adaptable to other systems and processes such as the adult criminal justice system, mental health services, health care screening and treatment, STI testing and treatment, child welfare, education, and other service systems. The Cascade is an example of how articulating an overarching framework can be used to harmonize measurement across diverse sites and systems, and inform the development of new measures related to cross-systems coordination and systems integration. 


\subsection{Limitations}

We are aware that the Cascade model simplifies what can be a complex process, but in developing the model (in collaboration with our JJ and BH agency project partners), we determined that a graphically clear, straightforward depiction of the process was important to enable agency staff, including line staff as well as supervisors and administrators, to clearly see the sequential nature of the process and key transition points. Indeed, as we have implemented the Cascade across $35 \mathrm{JJ}$ systems over the past 18 months, we have found that providers and $\mathrm{JJ}$ agency staff understand what it represents, and have found it quite useful in guiding the use of data to make meaningful changes in their screening, assessment, referral, and treatment process for youth under community supervision.

As discussed earlier, we also recognize that because delinquent youth often have comorbid mental health and other problems in addition to SUDs, assessing for multiple issues and identifying and linking these youth to appropriate treatment services can be a complicated and difficult undertaking. Although the Cascade is a helpful starting point for summarizing and studying the process of SU treatment service delivery, it cannot necessarily account for all of the complexities in providing optimal and timely treatment of comorbid conditions.

Given the limitations of $\mathrm{JJ}$ management information systems and the current difficulties many agencies have in linking JJ and services data, part of the JJ-TRIALS study protocol included an active researcher role in helping sites initially use the Cascade and collect the relevant data. As noted earlier, several sites have made permanent changes in their information systems to allow for continuing collection and reporting of Cascade data. In half of the sites, JJ-TRIALS facilitators provide active support to assist organizations in using and adapting the Cascade-based tools as they pursue different goals. Although sustainability is a key focus of JJ-TRIALS and several tools were developed to facilitate use of the Cascade by sites, in non-research settings it may be difficult for agencies to obtain the full benefits of using the Cascade framework to model and study their SU treatment delivery system. At the end of the study period, NIDA plans to post JJ-TRIALS materials to the NIDA website to allow other jurisdictions to use and adapt them as needed.

Finally, although the Cascade measures employ some qualitative dimensions related to the timing and quantity of services, it does not directly address treatment quality. However, the JJ-TRIALS trainings emphasize and provide substantive material on EBPs in prevention, screening, assessment, treatment, and interagency collaboration. In future development of the Cascade, we hope to enhance the framework to account for and measure use of EBPs and additional measures of service quality.

\subsection{Conclusions}

We developed the Cascade framework with the goal of serving both research and practice needs. A key goal of JJ-TRIALS has been to understand how the Cascade can facilitate the use of process improvement goals and measures to improve access to appropriate SU treatment services to young offenders in the community. Qualitative interviews and other data collection activities from the study will provide insights regarding how well these tools worked in different field settings. In turn, these lessons learned could lead to future studies 
aimed at enhancing the sustainability and dissemination potential of the Cascade for wider use within JJ settings.

As the use of the Cascade continues in the JJ-TRIALS research cooperative, new insights are expected in terms of its utility for guiding $\mathrm{JJ}$ and $\mathrm{BH}$ agencies in identifying unmet substance use service needs among delinquent youth under community supervision, and developing and testing organizational and policy changes to reduce those unmet needs. Moreover, the data collected on the multiple steps in the Cascade will be used to test key hypotheses about the impact of different implementation interventions on the ability to reduce unmet substance use service needs across the JJ-TRIALS sites. It is also likely that other challenges may arise as we continue to implement the Cascade and agencies gain more experience in using it for process improvement efforts.

As previously highlighted, the current version of the Cascade focuses on substance abuse service delivery system. Future efforts need to expand the attention to linking assessment needs to various treatment types as part of an overall strategy to provide integrated care models. This is especially important given the multidimensional needs of delinquent youth that frequently require both treatment for substance abuse and mental health services. We are currently testing the Cascade framework for SUD services. But meeting the various BH needs of delinquent youth is a challenge that $\mathrm{JJ}$ agencies need to address. Lessons from the JJ-TRIALS should be informative as to how to build organizational links to provide more comprehensive services for youth.

The ultimate goal of a collaborative and coordinated JJ-BH "meta-system" is to maximize the proportion of substance-involved youth who are identified, referred, initiated, and retained in substance use treatment for a sufficient period of time to achieve clinically meaningful effects. Full engagement in appropriate services will provide both public health and public safety benefits, given the connection between substance use and delinquency (Belenko \& Logan, 2003; Evans-Cuellar et al., 2006; Hoeve et al., 2013; Wasserman et al., 2010; Zhang, 2004). Even in the early phases of JJ-TRIALS, the Cascade has proven to be a valuable heuristic tool for conceptualizing a complex multi-system and multi-site service delivery system and informing both researchers and practitioners about the processes for providing substance use services to youth in the JJ system and measuring their impacts and interconnections. It is hoped that these experiences will be empowering and reinforce continued use of the Cascade framework and it associated tools and procedures after the JJTRIALS study ends.

\section{Acknowledgments}

This study was funded under the Juvenile Justice Translational Research on Interventions for Adolescents in the Legal System project (JJ-TRIALS) cooperative agreement, funded by the National Institute on Drug Abuse (NIDA), National Institutes of Health (NIH). The authors gratefully acknowledge the collaborative contributions of NIDA and support from the following grant awards: Chestnut Health Systems (U01DA036221); Columbia University (U01DA036226); Emory University (U01DA036233); Mississippi State University (U01DA036176); Temple University (U01DA036225); Texas Christian University (U01DA036224); and University of Kentucky (U01DA036158). NIDA Science Officer on this project is Tisha Wiley. The contents of this publication are solely the responsibility of the authors and do not necessarily represent the official views of the NIDA, NIH, or the participating universities or juvenile justice systems. 


\section{References}

Aarons GA, Hurlburt M, Horwitz SM. Advancing a conceptual model of evidence-based practice implementation in public service sectors. Administration and Policy in Mental Health and Mental Health Services Research. 2011; 38:4-23. [PubMed: 21197565]

American Society of Addiction Medicine. The ASAM criteria: Treatment criteria for addictive, substance-related, and co-occurring conditions. Chevy Chase, MD: Author; 2013.

Barnes GM, Welte JW, Hoffman JH. Relationship of alcohol use to delinquency and illicit drug use in adolescents: Gender, age, and racial/ethnic differences. Journal of Drug Issues. 2002; 32(1):153178.

Belenko S, Dembo R. Treating adolescent substance abuse problems in the juvenile drug court. International Journal of Law and Psychiatry. 2003; 26:87-110. [PubMed: 12554002]

Belenko S, Logan TK. Delivering effective treatment to adolescents: Improving the juvenile drug court model. Journal of Substance Abuse Treatment. 2003; 25:189-211. [PubMed: 14670524]

Belenko S, Sprott J, Petersen C. Drug and alcohol involvement among minority and female juvenile offenders: Treatment and policy issues. Criminal Justice Policy Review. 2004; 15:336.

Boesky L. Mental health training in juvenile justice: A necessity. Corrections Today. 2001; 63(5):98101.

Burney-Nissen L, Butts J, Merrigan D, Kraft MK. The RWJF Reclaiming Futures initiative: Improving interventions for justice-involved youth. Juvenile and Family Court Journal. 2006; 57:39-52.

Chan YF, Dennis ML, Funk RR. Prevalence and comorbidity of major internalizing and externalizing problems among adolescents and adults presenting to substance abuse treatment. Journal of Substance Abuse Treatment. 2008; 34:14-24. [PubMed: 17574804]

Childs K, Sullivan CJ. Adolescent problem behavior: an investigation of underlying structure and possible transitions. Criminal Justice and Behavior. 2013; 40:57-79.

Clark DB. The natural history of adolescent alcohol use disorders. Addiction. 2004; 99(Suppl 2):5-22.

Damschroder L, Aron D, Keith R, Kirsh S, Alexander J, Lowery J. Fostering implementation of health services research findings into practice: a consolidated framework for advancing implementation science. Implementation Science. 2009; 4(1):50. [PubMed: 19664226]

Dansereau DF, Simpson DD. A picture is worth a thousand words: The case for graphic representations. Professional Psychology: Research \& Practice. 2009; 40(1):104-110.

De Leon, G., Jainchill, N. Recovery-oriented integrated system for juvenile justice clients. In: Jainchill, N., editor. Understanding and treating adolescent substance use disorders. Kingston, NJ: Civic Research Institute; 2012. Chapter 17

Drake, EK. "What works" in community supervision: Interim report. Document No. 11-12-1201. Olympia: Washington State Institute for Public Policy; 2011.

Englund MM, Egeland B, Oliva EM, Collins WA. Childhood and adolescent predictors of heavy drinking and alcohol use disorders in early adulthood: a longitudinal developmental analysis. Addiction. 2008; (103 Suppl 1):23-35. [PubMed: 18426538]

Evans-Cuellar A, Wasserman GA, McReynolds LS, Ko SJ, Katz LM. Can mental health treatment diversion reduce crime among youth? Journal of Policy Analysis and Management. 2006; 25(1): 197-214. [PubMed: 16465707]

Furdella, J., Puzzanchera, C. Delinquency cases in juvenile court, 2013. NCJ 248899. Washington DC: U.S. Department of Justice, Office of Juvenile Justice and Delinquency Prevention; 2015.

Gardner EM, McLees MP, Steiner JF, Del Rio C, Burman WJ. The spectrum of engagement in HIV care and its relevance to test-and-treat strategies for prevention of HIV infection. Clinical and Infectious Diseases. 2011; 52:793-800.

Garnick DW, Lee MT, O'Brien PL, Panas L, Ritter GA, Acevedo A, Garner BR, Funk RR, Godley MD. The Washington circle engagement performance measures' association with adolescent treatment outcomes. Drug and Alcohol Dependence. 2012; 124(3):250-258. [PubMed: 22364777]

Greenberg AE, Hader SL, Masur H, Young AT, Skillicorn J, Dieffenbach CW. Fighting HIV/AIDS in Washington, D.C. Health Affairs. 2009; 28:1677-87. [PubMed: 19887408] 
Grisso T, Barnum R, Fletcher K, Cauffman E, Peuschold D. Massachusetts youth screening instructurment for mental health needs of juvenile justice youth. Journal of American Academcy of Child \& Adolescent Pscyhiatry. 2001; 40(5):541-548.

Henderson CE, Taxman FS. Competing values among criminal justice administrators: The importance of substance abuse treatment. Drug and Alcohol Dependence. 2009; (103 Suppl 1):S7-S16. [PubMed: 19054632]

Henggeler SW, Clingempeel WG, Bronidon MJ, Pickrel SG. Four-year follow-up of multisystemic therapy with substance abusing and dependent juvenile offenders. Journal of the American Academy of Child and Adolescent Psychiatry. 2002; 41:868-874. [PubMed: 12108813]

Hicks BM, Iacono WG, McGue M. Consequences of an adolescent onset and persistent course of alcohol dependence in men: Adolescent risk factors and adult outcomes. Alcohol Clinical and Experimental Research. 2010; 34:819-833.

Hoeve M, McReynolds LS, Wasserman GA. Service referral for juvenile justice youths: Associations with psychiatric disorder and recidivism. Administration and Policy in Mental Health and Mental Health Services Research. 2013; 41(3):379-389.

Hser YI, Grella CE, Hubbard RL, Hsieh SC, Fletcher BW, Brown BS, Anglin MD. An evaluation of drug treatments for adolescents in 4 US cities. Archives of General Psychiatry. 2001; 58(7):689_ 695. [PubMed: 11448377]

Hunter S, Griffin B, Booth M, Ramchand R, McCaffrey D. Assessing the generalizability of the C SAT-sponsored GAIN dataset: Are the CSAT sites representative of adolescent treatment programs in the U.S.? Journal of Substance Abuse Treatment. 2013; 46:238-243. [PubMed: 23988191]

Kandel, D., Davies, M. Progression to regular marijuana involvement: Phenomenology and risk factors for near-daily use. In: Glantz, M., Pickens, R., editors. Vulnerability to drug abuse. Washington, DC: American Psychological Association; 1992. p. 211-242.

Kandel, D., Yamaguchi, K. Stages of drug involvement in the U.S. population. In: Kandel, DB., editor. Stages and pathways of drug involvement: Examining the gateway hypothesis. New York: Cambridge University Press; 2002. p. 65-89.

Kandel D, Johnson J, Bird H, Weissman M, Goodman S, Lahey B, Schwab-Stone M. Psychiatric comorbidity among adolescents with substance use disorders: findings from the MECA Study. Journal of the American Academy of Child and Adolescent Psychiatry. 1999; 38:693-699. [PubMed: 10361787]

Knight D, Belenko S, Wiley T, Robertson A, Arrigona N, Dennis M. the JJ-TRIALS Cooperative. Study protocol: Juvenile Justice-Translational Research on Interventions for Adolescents in the Legal System (JJ-TRIALS). Implementation Science. :2016. in press.

Knudsen HK. Adolescent-only substance abuse treatment: Availability and adoption of components of quality. Journal of Substance Abuse Treatment. 2009; 36:195-204. [PubMed: 19000942]

Lehman WE, Fletcher BW, Wexler HK, Melnick G. Organizational factors and collaboration and integration activities in criminal justice and drug abuse treatment agencies. Drug and Alcohol Dependence. 2009; 103(Supplement 1):S65-S72. [PubMed: 19307068]

Lessler K. Health and educational screening of school-age children: Definition and objectives. American Journal of Public Health. 1972; 62(2):191-197. [PubMed: 5058858]

MacCarthy S, Hoffmann M, Ferguson L, Nunn A, Irvin R, Bangsberg D, Dourado I. The HIV care cascade: models, measures and moving forward. Journal of the International AIDS Society. 2015; 18(1):20634-20641. [PubMed: 26626715]

Marsh, J., Pane, J., Hamilton, L. Making sense of data-driven decision making in education: Evidence from recent RAND research. Santa Monica, CA: RAND; 2006.

Manuel JK, Hagedorn HJ, Finney JW. Implementing Evidence-based Psychosocial Treatment in Specialty Substance Use Disorder Care. Psychology of Addictive Behaviors. 2011; 25(2):225-237. [PubMed: 21668085]

McCarty D, Gustafson DH, Wisdom JP, Ford J, Choi D, Molfenter T, Cotter F. The Network for the Improvement of Addiction Treatment (NIATx): Enhancing access and retention. Drug and Alcohol Dependence. 2007; 88(2-3):138-145. [PubMed: 17129680] 
McGovern MP, Lambert-Harris C, Gotham H, Claus RE, Xie H. Dual diagnosis capability in mental health and addiction treatment services: An assessment of programs across multiple state systems. Administration and Policy in Mental Health. 2014; 41:205. [PubMed: 23183873]

McLellan AT, Meyers K. Contemporary addiction treatment: A review of systems of problems for adults and adolescents. Biological Psychiatry. 2004; 56(10):764-770. [PubMed: 15556121]

Models for Change. Mental health screening within juvenile justice: The next frontier. 2007. http:// www.modelsforchange.net/publications/198

Moule P, Evans D, Pollard K. Using the Plan-Do-Study-Act model: Pacesetters experiences. International Journal of Healthcare Quality Assurance. 2013; 26:593-600.

Mugavero MJ, Amico KR, Horn T, Thompson MA. The state of engagement in HIV care in the United States: from cascade to continuum to control. Clinical and Infectious Diseases. 2013; 57:1164-71.

National Commission on Quality Assurance. Improving quality and patient experience: The state of health care quality 2013. Washington DC: Author; 2013.

National Institute on Drug Abuse. Principles of adolescent substance use disorder treatment: A research-based guide. (NIH Publication No. 14-7953). Bethesda, MD: Author; 2014.

National Quality Forum. Behavioral Health, Phase 1. Washington DC: Author; 2012.

New York State Department of Health. Disease screening. 2015. https://www.health.ny.gov/diseases/ chronic/discreen.htm

Office of Applied Studies. Substance-abuse treatment in adult and juvenile correctional facilities: Findings from the uniform facility data set 1997 survey of correctional facilities (Drug and Alcohol Services Information System Series: S-9). Rockville, MD: Office of Applied Studies; 2000.

Office of Juvenile Justice and Delinquency Prevention. Model Programs Guide. 2016. Retrieved from http://www.ojjdp.gov/mpg

Office of National Coordinator. 2015. https://ecqi.healthit.gov/ep/2014-measures-2015-update/ initiation-and-engagement-alcohol-and-other-drug-dependence-treatment

Proctor E, Landsverk J, Aarons G, Chambers D, Glisson C, Mittman B. Implementation research in mental health services: An emerging science with conceptual, methodological, and training challenges. Administration and Policy in Mental Health and Mental Health Services. 2009; 36:2434.

Robinson ZD, Riggs PD. Cooccurring psychiatric and substance use disorders. Child and Adolescent Psychiatric Clinics of North America. 2016; 25:713-722. [PubMed: 27613347]

Roman JK, Butts JA, Roman CG. Evaluating systems change in a juvenile justice reform initiative. Children and Youth Services Review. 2011; 33:S41-S53.

Scott CK, Dennis ML. Results from two randomized clinical trials evaluating the impact of quarterly recovery management checkups with adult chronic substance users. Addiction. 2009; 104(6):959971. [PubMed: 19344441]

Scott, CK., Dennis, ML. Recovery Management Checkups with adult chronic substance users. In: Kelly, JF., White, WL., editors. Addiction recovery management: Theory, research and practice, current clinical psychiatry. New York, NY: Springer Science+Business Media, LLC; 2011. p. 87-101.

Scott, CK., Dennis, ML. Juvenile Justice National Survey preliminary findings and juvenile justice community supervision agency report: Feedback for participating agencies. Chicago, IL: Chestnut Health Systems; 2015.

Scott, CK., Dennis, ML. Preliminary Findings from the JJ-Trials National Surveys. Rockville, MD: Revised version of presentation at the National Institute on Drug Abuse (NIDA); 2016. April 13, 2016

Snyder, H., Sickmund, M. Juvenile offenders and victims: 2006 national report. Washington, DC: U.S. Department of Justice, Office of Justice Programs, Office of Juvenile Justice and Delinquency Prevention; 2006.

Steadman HJ. Boundary spanners: A Key component for the effective interactions of the justice and mental health systems. Law and Human Behavior. 1992; 16:75-87. 
Sterling S, Kline-Simon A, Wibbelsman C, Wong A, Weisner C. Screening for adolescent alcohol and drug use in pediatric health-care settings: predictors and implications for practice and policy. Addiction Science \& Clinical Practice. 2012; 7:13. [PubMed: 23186254]

Stone AL, Becker LG, Huber AM, Catalano RF. Review of risk and protective factors of substance use and problem use in emerging adulthood. Addictive Behaviors. 2012; 37:747-775. [PubMed: 22445418]

Swift W, Coffey C, Carlin JB, Degenhardt L, Patton GC. Adolescent cannabis users at 24 years: trajectories to regular weekly use and dependence in young adulthood. Addiction. 2008; 103:1361-1370. [PubMed: 18855826]

Substance Abuse and Mental Health Services Administration. TIP \#31. Screening and assessing adolescents for substance use disorders. 2015. http://www.ncbi.nlm.nih.gov/books/NBK64364/

Substance Abuse and Mental Health Services Administration. A guide to Evidence-Based Practices (EBP). Jan. 2016 Retrieved from http://www.samhsa.gov/ebp-web-guide

Taxman, FS. Reducing recidivism through a seamless system of care: Components of effective treatment, supervision, and transition services in the community. Washington, D.C: Office of National Drug Control Policy; 1998.

Taxman, FS., Belenko, S. Implementing evidence-based practices in community corrections and addiction treatment. New York, NY: Springer; 2012.

Taxman FS, Bouffard J. The importance of systems issues in improving offender outcomes: Critical elements of treatment integrity. Justice Research and Policy. 2000; 2:9-30.

Taxman FS, Caudy M. Risk tells us who, but not what or how: Empirical assessment of the complexity of criminogenic needs to inform correctional programming. Criminology and Public Policy. 2015; 14(1):71-103.

Taxman FS, Henderson C, Young D, Farrell J. The impact of training interventions on organizational readiness to support innovations in juvenile justice offices. Administration and Policy in Mental Health and Mental Health Services Research. 2014; 41:177-188. [PubMed: 23143081]

Taylor MJ, McNicholas C, Nicolay C, Darzi A, Bell D, Reed J. Systematic review of the of the plando-study-act method to improve quality in healthcare. BMJ Quality and Safety. 2014; 23:290-298.

Teplin LA, Elkington KS, McClelland GM, Abram KM, Mericle AA, Washbury J. Major mental disorders, substance use disorders, comorbidity, and HIV/AIDS risk behaviors in juvenile detainees. Psychiatric Services. 2005; 56:823-828. [PubMed: 16020814]

U.S. Department of Justice. Civil rights of institutionalized persons (CRIPA). 2016. Available at http:// www.justice.gov/crt/civil-rights-institutionalized-persons

Wachter, A. Mental health screening in juvenile justice. Pittsburgh, PA: National Center for Juvenile Justice; 2015.

Wasserman GA, Jensen PJ, Ko SJ, Trupin EW, Cocozza JJ. Mental health assessments in juvenile justice settings: Report of the Consensus Conference. Journal of the American Academy of Child and Adolescent Psychiatry. 2003; 42:752-761. [PubMed: 12819434]

Wasserman G, McReynolds L, Ko S, Katz L, Carpenter J. Gender differences in psychiatric disorders at Juvenile Probation Intake. American Journal of Public Health. 2005; 95(1):131-137. [PubMed: 15623873]

Wasserman GA, McReynolds LS, Whited AL, Keating JM, Musabegovic H, Huo Y. Evaluating Project Connect: Improving juvenile probationers' mental health and substance use service access. Administration and Policy in Mental Health and Mental Health Services Research. 2009; 36:393405. [PubMed: 19582568]

Wasserman GA, McReynolds LS, Schwalbe CS, Keating J, Shane A. Psychiatric disorder, comorbidity, and suicidal behavior in juvenile justice youth. Criminal Justice and Behavior. 2010; 37(12):1361-1376.

White House Office of National AIDS Policy. National HIV/AIDS strategy for the United States. Washington, DC: The White House; 2010. Available at http://www.whitehouse.gov/sites/default/ files/uploads/NHAS.pdf

Wilson, JMG., Jungner, G. Principles and practice of screening for disease. Geneva, Switzerland: World Health Organization; 1968. 
Winters KC, Lee CY. Likelihood of developing an alcohol and cannabis use disorder during youth: association with recent use and age. Drug and Alcohol Dependence. 2008; 92:239-247. [PubMed: 17888588]

Wissow L, Brown J, Fothergill K, Gadomski A, Hacker K, Salmon P, Zelkowitz R. Universal Mental Health Screening in Pediatric Primary Care: A Systematic Review. Journal of the American Academy of Child and Adolescent Psychiatry. 2013; 52(11):1134-1147. [PubMed: 24157388]

Young DW, Dembo R, Henderson CE. A national survey of substance abuse treatment for juvenile offenders. Journal of Substance Abuse Treatment. 2007; 32:255-266. [PubMed: 17383550]

Young DW, Farrell J, Taxman FS. Impacts of juvenile probation training models on youth recidivism. Justice Quarterly. 2013; 30(6):1068-1089.

Zhang, Z. Drug and alcohol use and related matters among arrestees, 2003. Washington, DC: U.S. Department of Justice, National Institute of Justice; 2004. 


\section{HIGHLIGHTS}

- $\quad$ Adolescent offenders have significant need for sub stance abuse treatment

- $\quad$ Agencies need systematic guidance for improving identification and referral of youth to services

- A Juvenile Justice Behavioral Health Services Cascade is proposed

- $\quad$ The Cascade helps identify unmet needs and areas for organizational intervention 


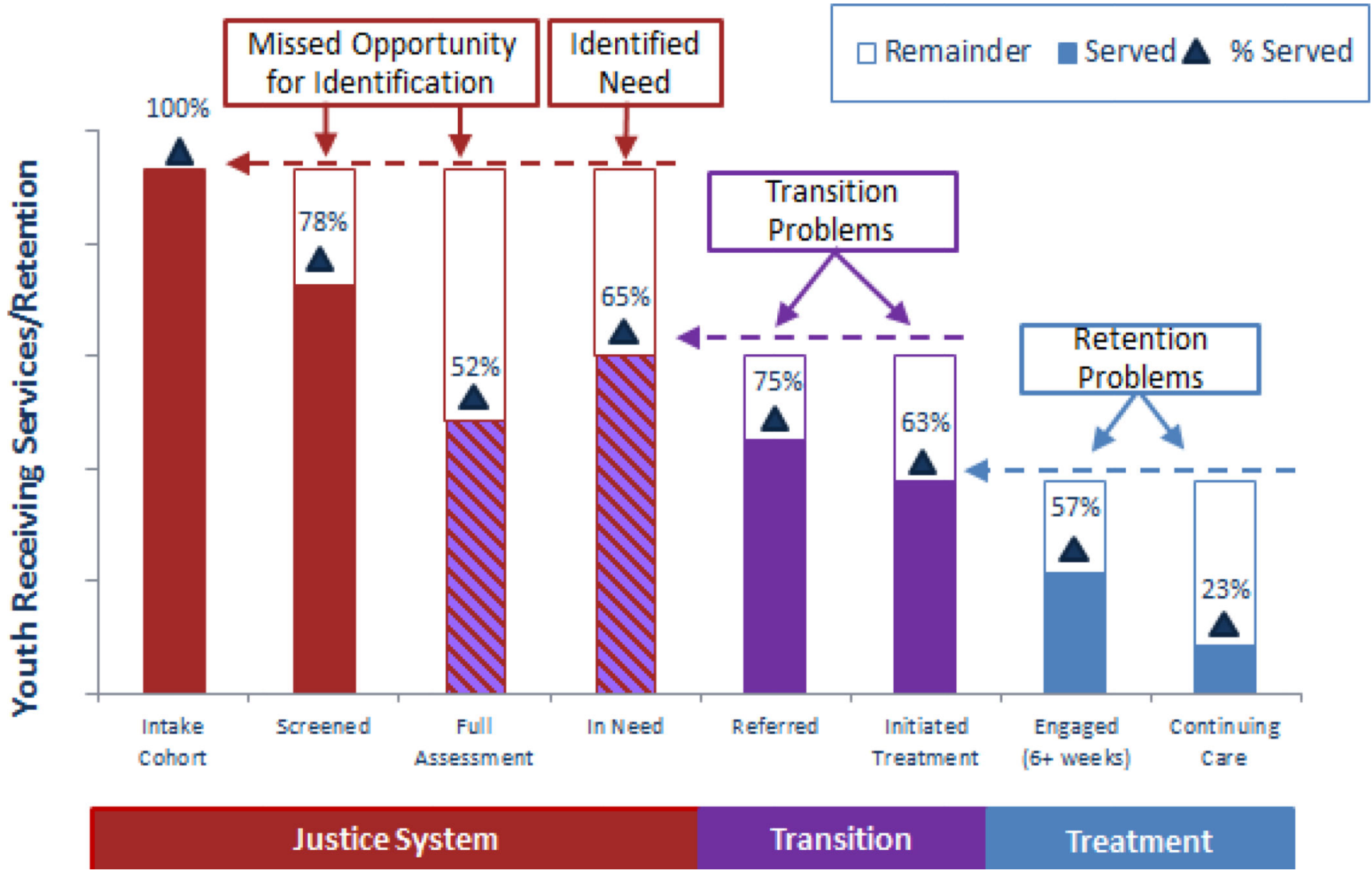

Figure 1.

Juvenile Justice Behavioral Health Services Cascade: Hypothetical Illustration of Unmet Needs for Youth under Community Juvenile Justice Supervision 
Table 1

\section{Behavioral Health Services Cascade Definitions}

\begin{tabular}{lll}
\hline Step & Operational Definition & Rate \\
\hline a. JJ Referrals & $\begin{array}{l}\text { Total number of referrals to juvenile justice in time period with a } \\
\text { disposition starts date, less any youth already in treatment at that time. }\end{array}$ & -- \\
\hline b. Screened & Subset of JJ referrals (a) with a screening date. & b/a \\
\hline $\begin{array}{l}\text { c. Clinical } \\
\text { Assessment }\end{array}$ & $\begin{array}{l}\text { Subset of JJ referrals (a) with a full clinical assessment (includes if } \\
\text { follow-up to screening or other clinical assessment) }\end{array}$ & c/a \\
\hline $\begin{array}{l}\text { d. Need } \\
\text { Identified }\end{array}$ & $\begin{array}{l}\text { Subset of JJ referrals (a) with a need for substance use treatment } \\
\text { based on screener, urinalysis, clinical assessment, or other sources } \\
\text { of information. }\end{array}$ & $\mathrm{d} / \mathrm{a}$ \\
\hline $\begin{array}{l}\text { e. JJ Referrals } \\
\text { to Treatment }\end{array}$ & $\begin{array}{l}\text { Subset of those in need (d), referred by the juvenile justice system } \\
\text { to substance use treatment. }\end{array}$ & $\mathrm{e} / \mathrm{d}$ \\
\hline $\begin{array}{l}\text { f. Initiated } \\
\text { Treatment }\end{array}$ & $\begin{array}{l}\text { Subset of those referred to treatment (e) who have treatment start } \\
\text { date. }\end{array}$ & $\mathrm{f} / \mathrm{e}$ \\
\hline $\begin{array}{l}\text { g. Engaged In } \\
\text { Treatment }\end{array}$ & $\begin{array}{l}\text { Subset of those who initiate treatment (f) who stay in treatment for } \\
\text { at least 6 weeks (based on treatment discharge minus treatment } \\
\text { start date). }\end{array}$ & $\mathrm{g} / \mathrm{f}$ \\
\hline $\begin{array}{l}\text { Subset of those engaged in treatment (g) that are still getting } \\
\text { Care }\end{array}$ & \begin{tabular}{l} 
treatment after 90 days (whether via retention, transfer or booster). \\
\hline
\end{tabular} & $\mathrm{h} / \mathrm{g}$ \\
\hline
\end{tabular}




\section{Table 2}

Service Cascade Timing and Quality Measures

\begin{tabular}{|c|c|c|c|}
\hline $\begin{array}{l}\text { Service } \\
\text { Cascade Step }\end{array}$ & Timing & $\begin{array}{l}\text { Quality } \\
\text { Indicators }\end{array}$ & \\
\hline a. Referred & NA & $\bullet$ & NA \\
\hline b. Screened & $\begin{array}{l}\text { Days between intake } \\
\text { and screen } \\
\text { (target: } 30 \text { days) }\end{array}$ & $\begin{array}{l}\cdot \\
\cdot \\
\cdot \\
-\end{array}$ & $\begin{array}{l}\text { Use of a psychometrically sound screening instrument } \\
\text { Use of } 2+\text { sources of corroborating evidence } \\
\text { Training and quality assurance provided to staff } \\
\text { Screening results used to inform referral to full clinical assessment and/or treatment }\end{array}$ \\
\hline $\begin{array}{l}\text { c. Clinical } \\
\text { Assessment }\end{array}$ & $\begin{array}{l}\text { Days between intake } \\
\text { and assessment } \\
\text { (target: } 30 \text { days) }\end{array}$ & $\begin{array}{l}\cdot \\
\text { - } \\
\text { - } \\
\text { - } \\
\text { - }\end{array}$ & $\begin{array}{l}\text { Use of a psychometrically sound clinical instrument } \\
\text { Use of } 2+\text { sources of corroborating evidence } \\
\text { Training and quality assurance provided to staff on administration and interpretation } \\
\text { Assessment results used to inform placement plans } \\
\text { Qualifications of staff doing assessment }\end{array}$ \\
\hline $\begin{array}{l}\text { d. Need } \\
\text { Identified }\end{array}$ & $\begin{array}{l}\text { Days between intake } \\
\text { and determination of } \\
\text { need (target: } 14 \text { days } \\
\text { from last of } \mathrm{b} / \mathrm{c} \text { ) }\end{array}$ & • & $\begin{array}{l}\text { Determined by results of a psychometrically sound screening or assessment } \\
\text { instrument } \\
\text { Documentation of need in record/service plan } \\
\text { Communication of needs across system (e.g., judge, PO) }\end{array}$ \\
\hline $\begin{array}{l}\text { e. JJ Referred to } \\
\text { Treatment }\end{array}$ & $\begin{array}{l}\text { Days between } \\
\text { determined need and } \\
\text { referral } \\
\text { (target: } 14 \text { days) }\end{array}$ & $\begin{array}{l}\cdot \\
\cdot \\
\cdot \\
\bullet\end{array}$ & $\begin{array}{l}\text { "Quality" of services (i.e., licensed/ accredited/ certified) } \\
\text { Match between client needs and service intensity } \\
\text { Program contact provided } \\
\text { Active referral (e.g., Phone call made; transportation provided) }\end{array}$ \\
\hline $\begin{array}{l}\text { f. Initiated } \\
\text { Treatment }\end{array}$ & $\begin{array}{l}\text { Days between } \\
\text { referral and first } \\
\text { session } \\
\text { (target: } 14 \text { days) }\end{array}$ & $\bullet$ & $\begin{array}{l}\text { Use of evidenced-based treatment approach } \\
\text { Sharing information (e.g., documentation of first session confirmed by service } \\
\text { agency) }\end{array}$ \\
\hline $\begin{array}{l}\text { g. Engaged In } \\
\text { Treatment }\end{array}$ & $\begin{array}{l}\text { Measure based on } 6 \\
\text { or more weeks in } \\
\text { treatment }\end{array}$ & $\begin{array}{l}\cdot \\
\cdot \\
\cdot \\
\cdot \\
\cdot\end{array}$ & $\begin{array}{l}\% \text { of Youth receiving } 3+\text { sessions within first } 6 \text { weeks } \\
\text { Treatment completion/ discharge status } \\
\% \text { youth receiving treatment services from JJ agency } \\
\text { Qualifications of staff providing treatment services } \\
\text { Sharing information (e.g., documentation of multiple sessions confirmed by service } \\
\text { agency) }\end{array}$ \\
\hline $\begin{array}{l}\text { h. Continuing } \\
\text { Care }\end{array}$ & $\begin{array}{l}\text { Measure based on } 90 \\
\text { or more days in any } \\
\text { kind of treatment }\end{array}$ & $\begin{array}{l}\bullet \\
\bullet \\
\bullet\end{array}$ & $\begin{array}{l}\text { Retention/dosage within each episode } \\
\text { Service intensity across episodes } \\
\text { Sharing information (e.g., documentation of attendance confirmed by service agency) }\end{array}$ \\
\hline
\end{tabular}

J Subst Abuse Treat. Author manuscript; available in PMC 2018 March 01. 